Available online at: https://proceeding.researchsynergypress.com/index.php/cpmhs/index

RSF Conference Series: Medical and Health Science

e-ISSN (to be processed) / p-ISSN (to be processed)

Volume 1 Number 1 (2021): 135-145

\title{
Extra Virgin Olive Oil Nanoemulsion Attenuated Inflammatory Response in LPS-Induced Sepsis
}

\section{Anna Surgean Veterini' ${ }^{1}$, Nancy Margarita Rehatta ${ }^{1}$, Subijanto Marto Soedarmo', Heni Rachmawati ${ }^{1}$, Widjiati' ${ }^{\text {, Widodo Jatim P1 }}$, Annis Catur Adi' ${ }^{1}$ I Ketut Sudiana ${ }^{1}$}

\author{
${ }^{1}$ Airlangga University, Indonesia
}

\begin{abstract}
The provision of nutritional components in critical illness such as sepsis remains a big issue in clinical application, particularly through oral route due to intestinal integrity damaged-associated absorption problem. The aim of this research was to develop an EVOO nanoemulsion as a nutrient carrier to improve its permeability while maintaining intestinal mucosa integrity in a mouse model of LPS-induced endotoxemia. EVOO nanoemulsion was prepared by using the ultrasonication-mild agitation method. EVOO nanoemulsion $(1.5 \mathrm{~mL}$ ) was administered to the mice via an orogastric tube. The effect of EVOO nanoemulsion was evaluated by assessing the histopathological alterations in the lung, measuring the activation of NFGB-p65, the levels of circulating SP-D, TNF- $\alpha$, IL-8, and IL-10. The main result, EVO0 nanoemulsion decreased circulating SP-D level after 24h. In conclusion, EVOO nanoemulsion is a promising carrier to improve nutrient absorption and decrease circulating SP-D as an organ injury biomarker.
\end{abstract}

Keywords: Olive oil; Nanoemulsion; Nano nutrition; Enteral nutrition; Translational nutrition research; Sepsis

This is an open access article under the CC-BY-NC license

\section{INTRODUCTION}

Administration of enteral nutrition in a critically ill patient often encounters absorption problems. Several benefits derived from EN formed the basis for selecting the route of nutrition in this study. One of the advantages is the prevention of bacterial translocation and stress ulcerations. In this study, the potential benefit of EVOO nanoemulsion in a mouse model of LPS-induced sepsis was evaluated. A chronic inflammatory condition was indicated by increased blood levels of both pro-and anti-inflammatory mediators. To demonstrate the effect of EVOO nanoemulsion on this disease model, an assessment of the levels of inflammatory mediators as well as SP-D was conducted.

\section{LITERATURE REVIEW}

Under basal conditions, the intestinal epithelium absorbs nutrients and plays a critical role as the first-line protection against pathogenic microbes and as the central coordinator of mucosal immunity (Otani and Coopersmith, 2019; van Haren et al., 2007). However, there is impaired absorption of nutrients in sepsis and critically ill patient. In addition, gastric emptying is delayed to some extent in almost all critically ill patients, with many having intestinal ileus, particularly after surgery. This may be compounded by opioids used for analgesia or sedation, which further reduce gastric emptying and gut peristalsis. Hypoperfusion, venous congestion, mucosal edema, motility dysfunction, continuous feeding regimens, 
nasogastric suctioning, and changes in intraluminal $\mathrm{pH}$ are all factors that affect GI absorption (alkalinization). The use of vasoactive agents for circulatory support may also decrease splanchnic blood flow, gut perfusion, and, therefore absorption (Charlton and Thompson, 2019).

To overcome the abovementioned issue, the nutrient was formulated into nanoemulsion in this study. Extra virgin olive oil (EVOO) is one of the most consumed food ingredients. The bioactive in EVOO that play a role in multiple positive effects on humans and animals are oleic acid and hydroxytyrosol (Jimenez-Lopez et al., 2020). Administration of EVOO nanoemulsion was expected to improve pharmacokinetics and pharmacodynamics in critically ill patients.

An in vivo study using a mouse model of breast cancer showed the effect of EVOO phenolics nanoemulsion in suppressing tumor growth by $90 \%$ (Siddique et al., 2019). The results in the afore mentioned study indicated the potential use of EVOO phenolic formulations for therapeutic and dietary applications.

\section{RESEARCH METHODOLOGY}

Materials used to prepare EVOO nanoemulsion are chremofor RH40, PEG 400, and distilled water, while foods given to the mice were in the form of pellets.

Nanoemulsion was produced in the School of Pharmacy ITB. The EVOO brand (Leccino) was chosen for this research because it was proven that this brand has the highest phenol content (Bayram et al., 2012). The process and manufacture of EVOO nanoemulsion using the ultrasonication-mild agitation method have been submitted for publication. The physical characterization of EVOO nanoemulsion consisted of globule size and polydispersity index determination using Particle Size Analyzer.

Male Mus musculus mice, 10 - 12 weeks, were obtained from the Laboratory of Experimental Animals Universitas Gadjah Mada. The mice underwent acclimatization for a week with adequate food and lighting. Mice were excluded from the experiment if the general condition seemed weak before the experiment or if mice appeared aggressive. Drop-out criteria included the death of the mice during the intervention period. The mice were divided into ten different groups (Table 1).

Table1. Mice Group

\begin{tabular}{cccc}
\hline Group & Induction* & Treatment & Time observed after induction (h) \\
\hline K1 & - & - & 1 \\
K2 & LPS & - & \\
\hline K3 & - & EVOO nanoemulsion & \\
K4 & - & - & 8 \\
K5 & LPS & EVOO nanoemulsion & \\
K6 & LPS & - & \\
\hline K7 & - & EVOO nanoemulsion & \\
K8 & - & - & 24 \\
K9 & LPS & EVOO nanoemulsion & \\
K10 & LPS & - & \\
\hline
\end{tabular}

*) The non-induced mice received PBS injection instead of LPS

Endotoxemia in mice was induced by intraperitoneal injection of LPS (Sigma, 0111:B4) $10 \mathrm{mg} / \mathrm{kg}$ body weight. The clinical adjustment of endotoxemia was adopted from the sepsis score by Gonçalves-deAlbuquerque's clinical score (Gonçalves et al., 2017). The clinical signs and scores that we examined were based on Medeiros' methodology (Medeiros-De-Moraes et al., 2018). To support the data for the 
occurrence of endotoxemia, the inflammatory responses were evaluated by measuring the circulating levels of TNF-? IL-8, IL-10 circulation using ELISA and lung tissue NFGB p65 activity by immunohistochemical staining. SP-D circulation was also measured to evaluate the markers of early organ failure.

EVOO nanoemulsion (1.5 ml) was administered to mice via orogastric tube 1 hour after intraperitoneal injection of LPS or PBS. According to table 1, there were four mice groups receiving EVOO nanoemulsion treatment, i.e., K3, K5, K7, and K9.

Hematoxylin and eosin (H\&E) staining was carried out to evaluate the evidence of acute lung injury. The obtained staining was observed under the Nikon Eclipse Ci microscope (400x). In addition, immunofluorescent staining was performed to detect NFOB p65. The obtained staining was observed under Confocal Laser Scanning Microscopy (Olympus FV1000). Protein expression of TNF-?], IL-8, IL-10, SP-D in mice serum were evaluated by using the ELISA method. One-way ANOVA was used to analyze the difference between groups. A two-sided statistical significance test is used to get all p-values.

\section{FINDINGS AND DISCUSSION}

Providing nutrition in the form of nanomedicine is one of the scientific breakthroughs to answer the challenge of impaired absorption of enteral nutrition in critical illness cases. The result from a computational study predicted that that oleic acid, the highest content of EVOO, has the most significant role on macrophages colony-stimulating factor agonists (Carpi et al., 2019). The protective effect of EVOO is due to the high oleic acid content and the antioxidant component of the polyphenolic compounds, including hydroxytyrosol (D'Angelo et al., 2001).

LPS-induced endotoxemia in mice was used as a model in this study to represent the condition of sepsis in humans. The sampling at $8 \mathrm{~h}$ represents the acute condition after intraperitoneal injection of LPS. Meanwhile, the $24 \mathrm{~h}$ sampling represents the end of the acute phase towards chronic conditions. After $1 \mathrm{~h}$, the abdomen temperature of LPS-induced mice increased significantly (Figure $1 ; \mathrm{p}<0.05$ ).

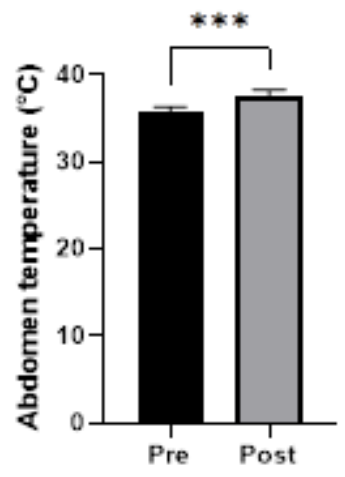

Figure 1. A significant increase in abdomen temperature of LPS-induce mice was observed $1 \mathrm{~h}$ after receiving an intraperitoneal injection of LPS $10 \mathrm{mg} / \mathrm{kg}$.

We performed the first histology examination with the H\&E staining method to see changes in lung injury features at various time points. At 1 hour after LPS injection, there were no significant changes in lung injury. However, changes in the reduction in acute lung injury scoring occurred in the LPS group given nano emulsion (Figure 3). An example of histological examination using the H\&E staining method is 
RSF Conference Series: Medical and Health Science, Vol. 1 (1), 135-145

Extra Virgin Olive Oil Nanoemulsion Attenuated Inflammatory Response in LPS-Induced Sepsis

Anna Surgean Veterini, Nancy Margarita Rehatta, Subijanto Marto Soedarmo, Heni Rachmawati, Widjiati, Widodo Jatim P,

Annis Catur Adi, I Ketut Sudiana

shown in Figure 2, which also showed pathological alterations that are characteristics of acute lung injury at $1 \mathrm{~h}$ after LPS induction.

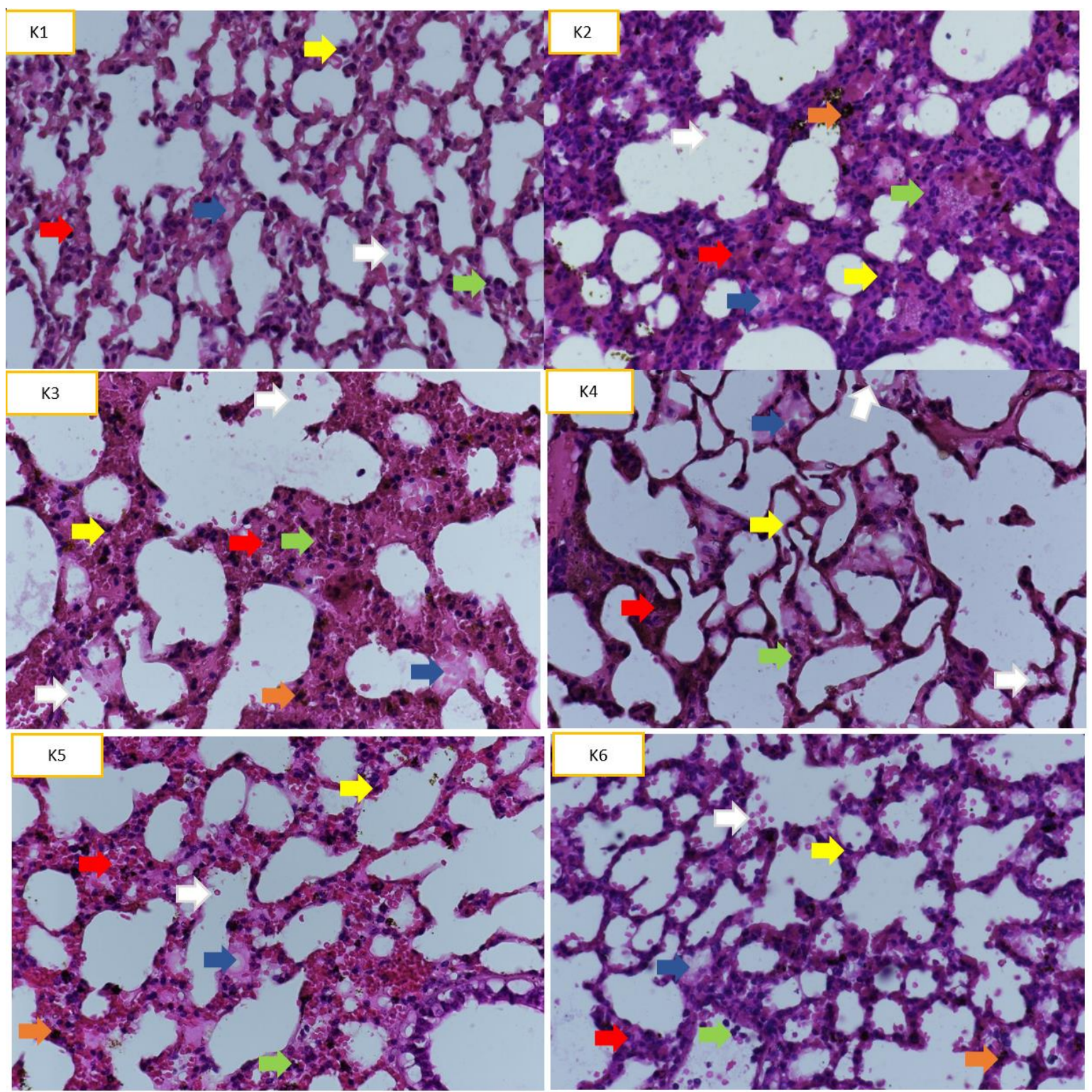


RSF Conference Series: Medical and Health Science, Vol. 1 (1), 135-145

Extra Virgin Olive Oil Nanoemulsion Attenuated Inflammatory Response in LPS-Induced Sepsis

Anna Surgean Veterini, Nancy Margarita Rehatta, Subijanto Marto Soedarmo, Heni Rachmawati, Widjiati, Widodo Jatim P, Annis Catur Adi, I Ketut Sudiana

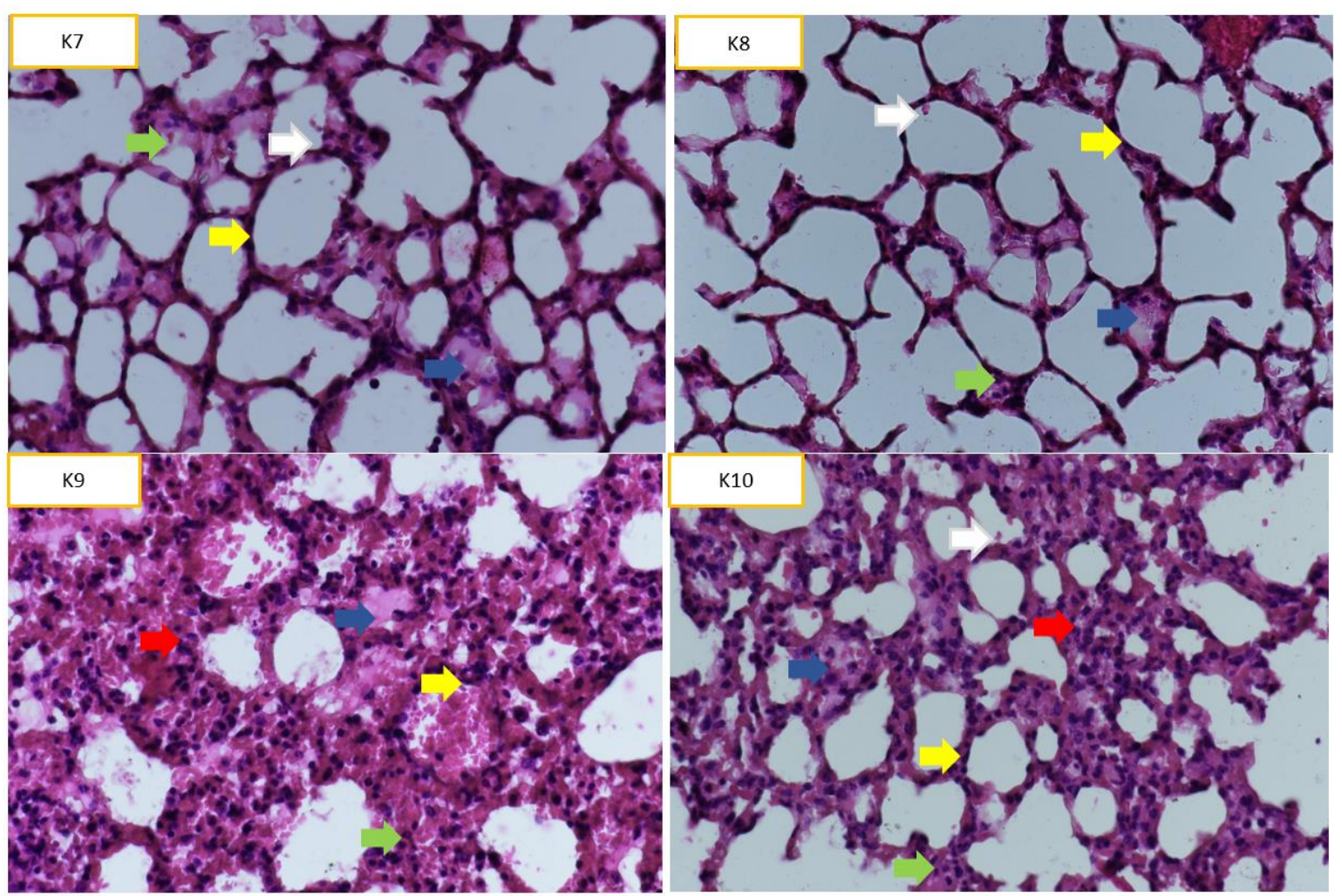

Figure 2. Histopathological features of the lung for various conditions. The red arrow indicated congestion. The blue arrow indicated pulmonary edema. White arrow indicated bleeding erythrocyte infiltration (hemorrhage) into the alveoli. Green arrows indicated the presence of inflammatory cell infiltration. Yellow arrows indicated alveolar necrosis. The orange arrow indicated the presence of alveolar macrophages (Nikon Eclipse Ci. DS-Ri2. 16 Megapixel).

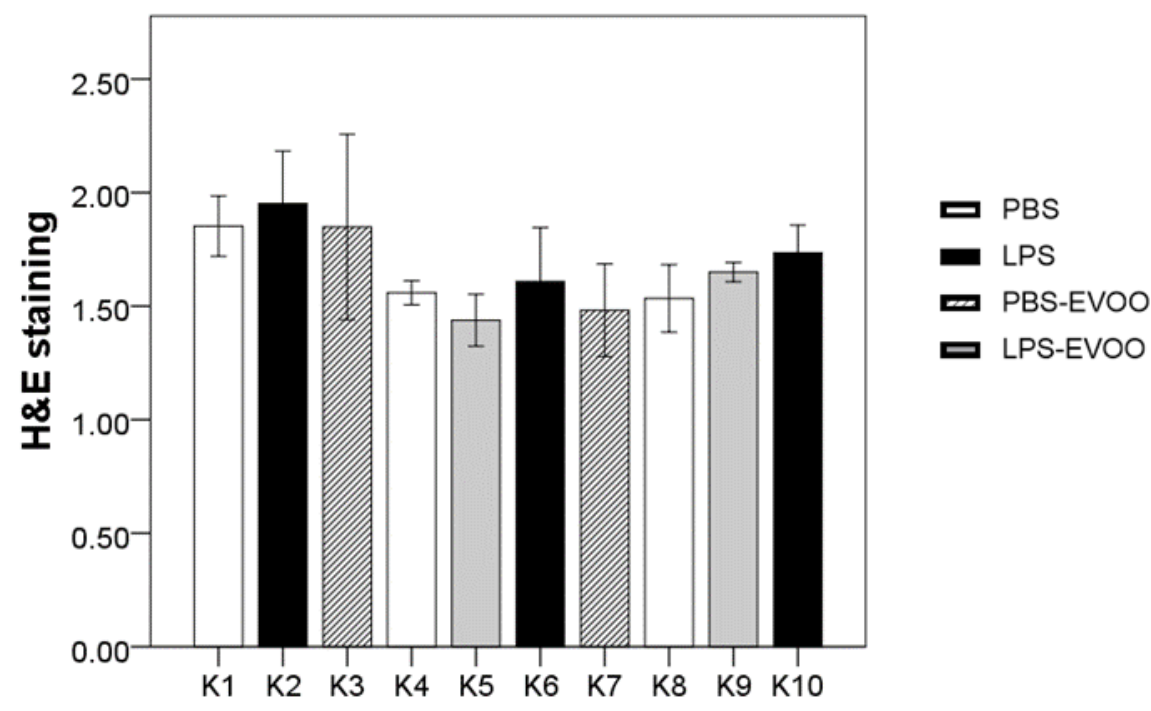


RSF Conference Series: Medical and Health Science, Vol. 1 (1), 135-145

Extra Virgin Olive Oil Nanoemulsion Attenuated Inflammatory Response in LPS-Induced Sepsis

Anna Surgean Veterini, Nancy Margarita Rehatta, Subijanto Marto Soedarmo, Heni Rachmawati, Widjiati, Widodo Jatim P, Annis Catur Adi, I Ketut Sudiana

Figure 3. Histopathological examination of the lung using the modified Eveillard (Eveillard et al., 2010) and Makiuchi (Makiuchi et al., 2007) scoring method. The data for each sample is the value observed in ten different fields of view at 200x and 400x magnifications.

The activity of NFQB-p65 was measured by determining the ratio between NF?B-p65 in the nucleus and cytoplasm (Yeo et al., 2017). The staining results were presented in Figure 4, and the ratio quantification was presented in Figure 5. It shows that at the early time of endotoxemia, there was a significant increase in NFOB-p65 activity, and a significant decrease in NF?B p65 activity occurred at 24thhour groups of endotoxemia mice given EVOO nanoemulsion (Figure 5).

The activation of the NF?B signaling pathway was evaluated by determining the expression of p65-NF?B using the immunohistochemistry technique. The activity of NF?B-p65 was determined by measuring the expression ratio between NF?B-p65 in the nucleus and cytoplasm.

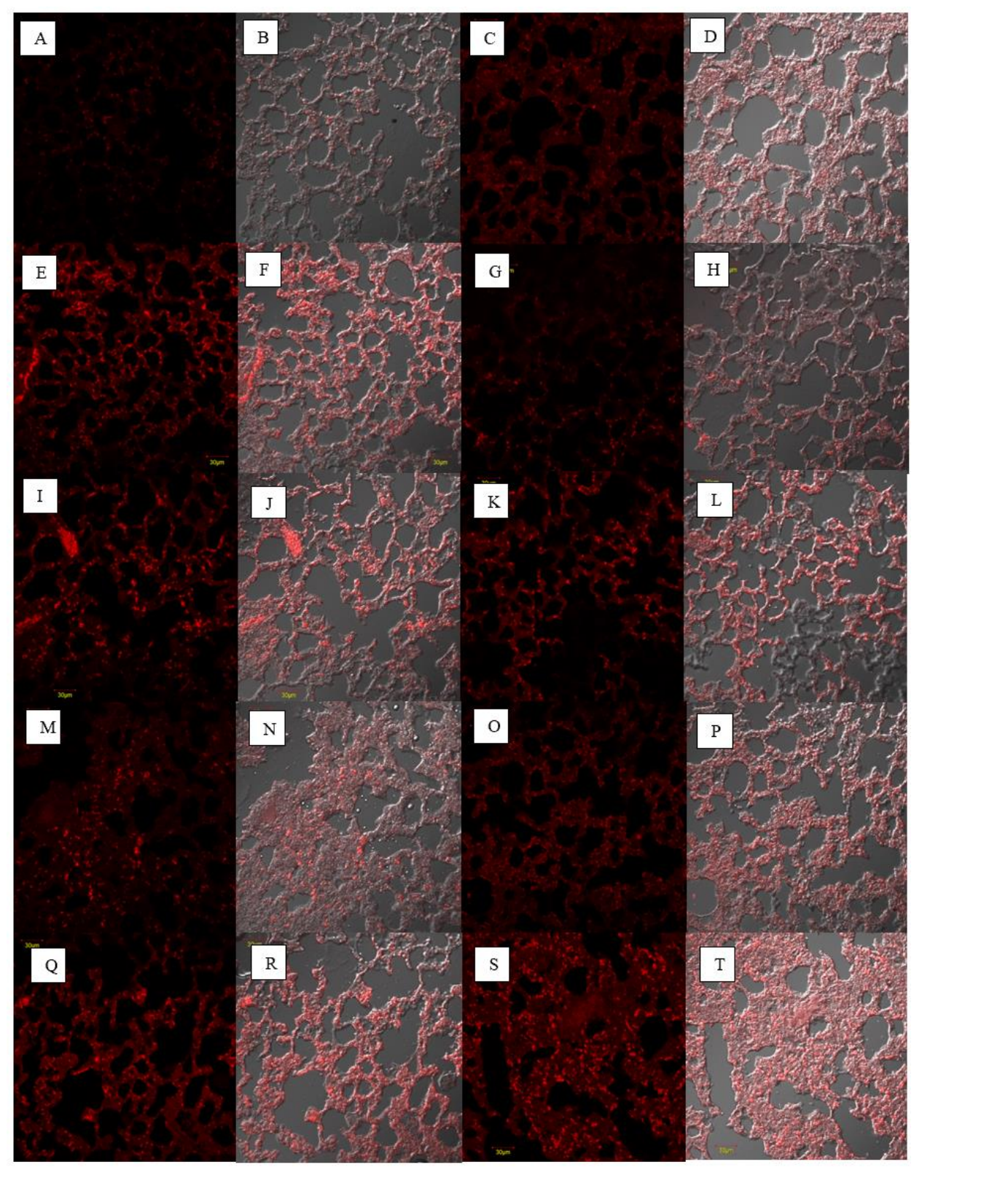


Figure 4. Examination of NFQB intensity p65 Lung Tissue with a Confocal Microscope. (A \& B) Mice Group K1, (C \& D) Mice Group K2, (E \& F) Mice Group K3, (G \& H) Mice Group K4, (I \& J) Mice Group K5, (K \& L) Mice Group K6, (M \& N) Mice Group K7, (O \& P) Mice Group K8, (Q \& R) Mice Group K9, and (S \& T) Mice Group K10.

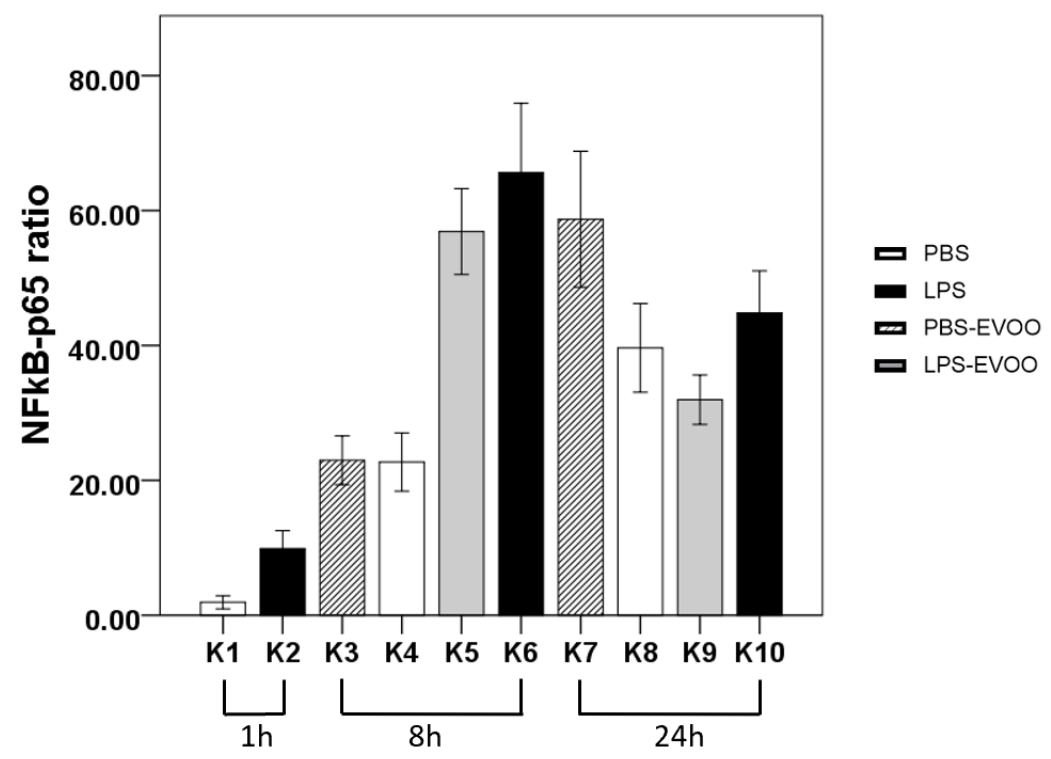

Figure 5. Nucleus/cytoplasm NFKB p65

The results showed that LPS significantly increased the NF?B-p65 activity in lung tissue after $1 \mathrm{~h}$. The control group showed increased activity of NF?B-p65 after 8h, but much lower compared to LPSinduced mice, which were not treated with EVOO. After 24h, the NFOB B-p65 activity was decreased in LPSinduced mice and significantly decreased in control mice. EVOO treatment affected the NF? B-p65 activity and decreased it in control mice after 24h. The effect of EVOO nanoemulsion on circulating TNF-? IL-8, IL-10, SP-D, and NF?B-p65 activity was evaluated after 8h and 24h (Figure 6).

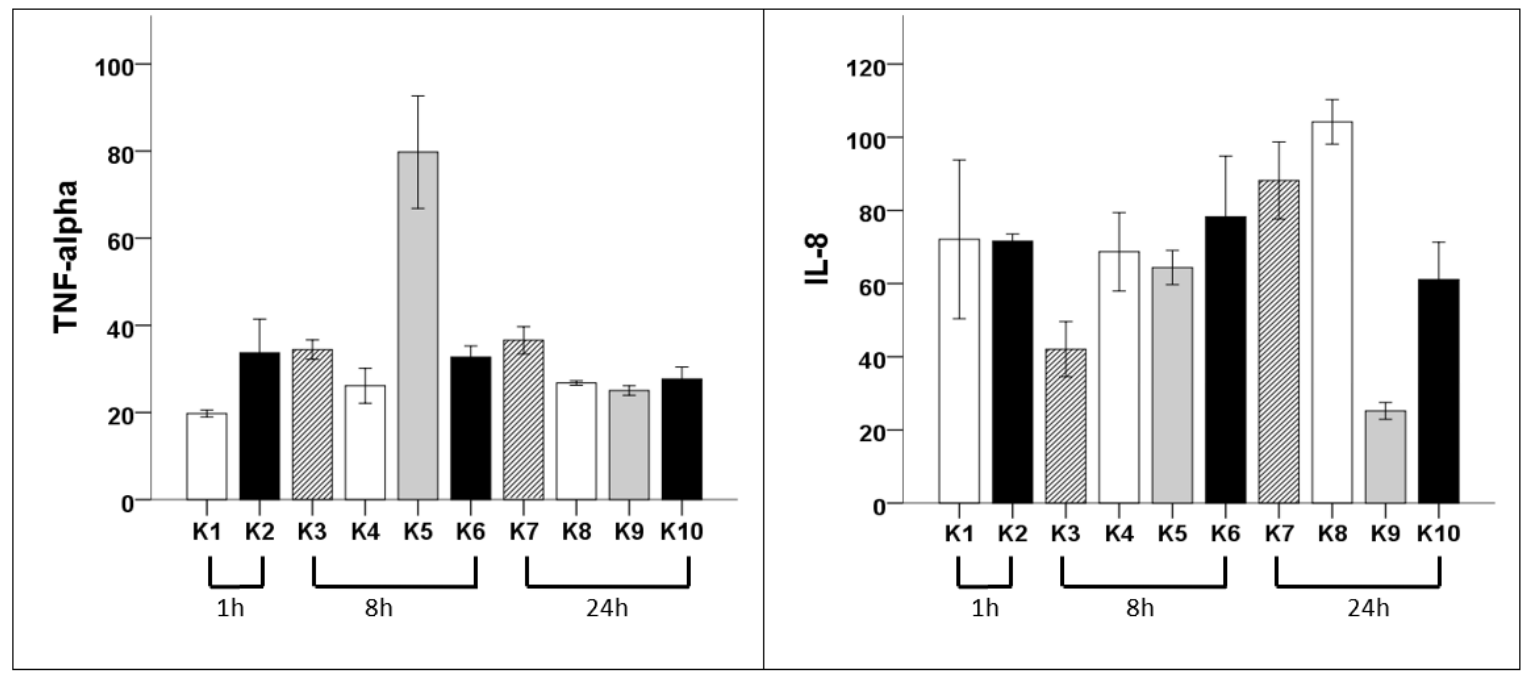




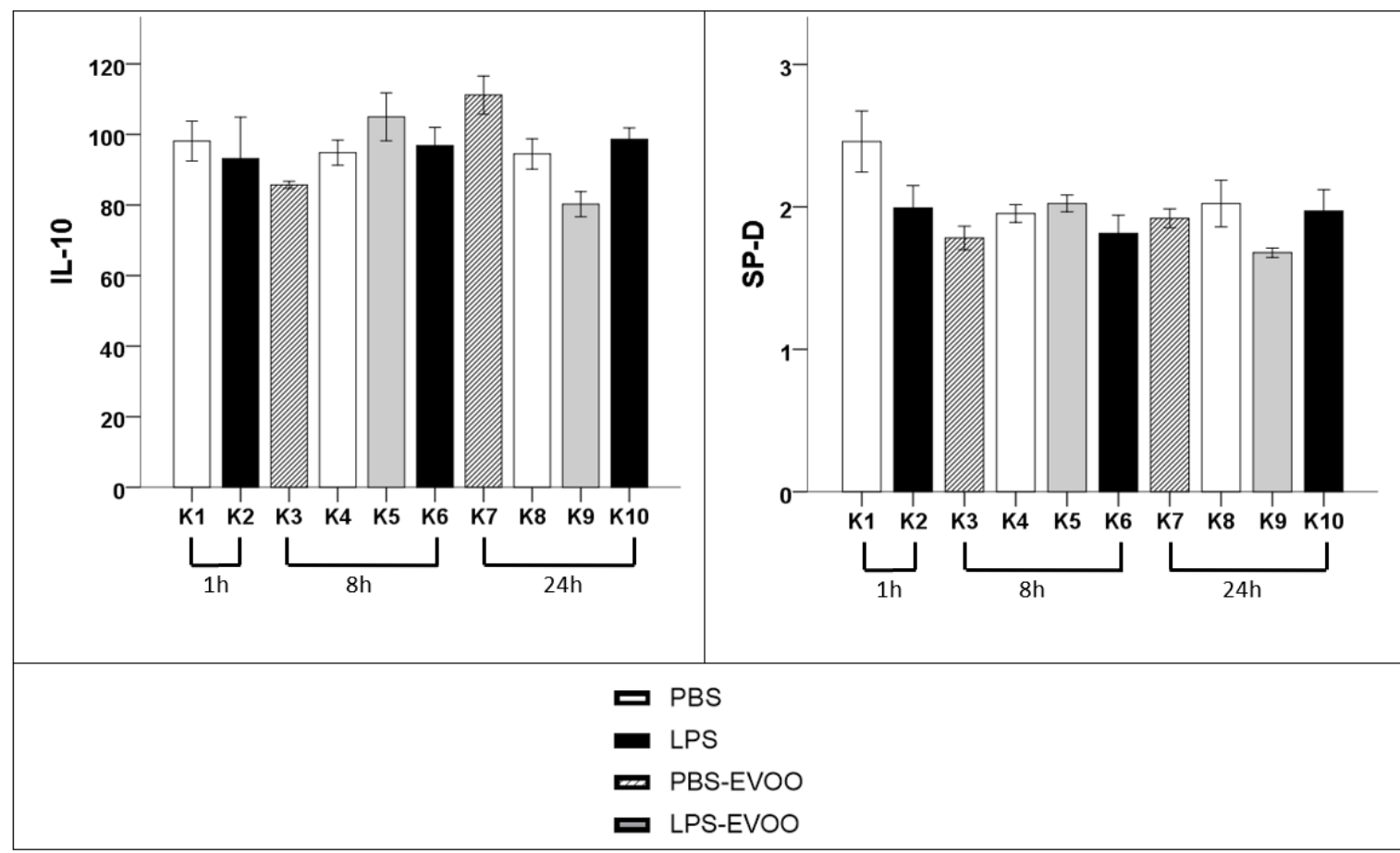

Figure 6. Circulating TNF- ?? IL-8 levels, IL-10, and SP-D levels were measured at 1, 8, and $24 \mathrm{~h}$ after LPS induction. Control mice received PBS instead of LPS. Each of control and LPS-induced mice was divided into two groups, i.e., the non-treated and EVOO-nanoemulsion-treated mice. The effect of EVOO nanoemulsion on control and LPS-induced mice was evaluated at 8 and $24 \mathrm{~h}$ after treatment.

Before EVOO treatment, the expression of TNF-? was significantly higher in mice at $1 \mathrm{~h}$ after LPSinduction (Figure 2; $\mathrm{p}<0.05$ ). However, the expression of SP-D was lower in LPS-induced mice, and there was no difference in the expression of IL-8 and IL-10 between LPS-induced mice and control (PBS) after $1 \mathrm{~h}$ (Figure 2). This result was in line with the proposal that TNF-? could orchestrate the production of other cytokines (Amiot et al., 1997).

As a pro-inflammatory cytokine used to evaluate sepsis patients, TNF-? is released from macrophages within 30 minutes after the inciting event, following gene transcription and RNA translation. Thus, this mediator is considered to be an early regulator of the immune response (Schulte et al., 2013). An elevated serum level of TNF- $\alpha$ has been found in up to $90 \%$ of sepsis patients (Girardin et al., 1988). In LPS-induced mice, the expression of TNF-? increased two times after $8 \mathrm{~h}$ but decreased again after 24h. This result was in agreement with other studies showing the rapid and transient induction of TNF-? by LPS (Georgescu et al., 2020; Kothari et al., 2013). In addition, it also supports the prognostic biomarker role in this cytokine. TNF-? production was also observed in control mice after $8 \mathrm{~h}$ but not as high as LPSinduced mice. An elevated TNF-? production was also observed in control mice after $8 \mathrm{~h}$ but not as high as LPS-induced mice, and it remained similar after $24 \mathrm{~h}$.

The effect of EVOO treatment was very profound in LPS-induced mice after 8h. EVOO attenuated TNF-? expression in LPS-induced mice. However, there was no difference in TNF-? expression of EVOOtreated and non-treated LPS-induced mice after $24 \mathrm{~h}$. This can be explained by the decreased TNF-? expression in LPS-induced mice after $24 \mathrm{~h}$, which showed that the inflammatory response might have been declined. EVOO treatment did not affect the TNF-? expression in control mice at any time. Thus, EVOO has 
a specific effect in reducing TNF-? expression only in inflamed mice. In agreement with our result, a study showed that mice receiving an olive oil-enriched diet were resistant to endotoxic shock and showed the lowest TNF-? expression compared to other mice (El Kamouni et al., 2017).

The results in Figure 6 showed that there was no significant difference in IL-8 expression of LPSinduced and control mice after $1 \mathrm{~h}$ and $8 \mathrm{~h}$, but a decrease in IL-8 expression was seen in all groups given EVOO nano emulsion and the peak of the decrease occurred at $24 \mathrm{~h}$. Interestingly, there was an increase of IL-8 levels in PBS groups after 24h. This might be due to the effect of the molecular clock or circadian clock (Curtis et al., 2015).

In this study, IL-10 expression was significantly higher in LPS-induced mice compared to control mice after $8 \mathrm{~h}$. This result was in line with several other studies showing that IL-10 production was enhanced several hours after TNF-? synthesis. A significant decreased in IL-10 expression was observed in LPS-induced mice after $24 \mathrm{~h}$. This low circulating IL-10 level supports the theory that IL-10 plays an important role in downregulating the potentially detrimental mediators, one of them is TNF-? (Barsig et al., 1995). Since TNF-? expression was already low after $24 \mathrm{~h}$, IL-10 production was also declined (Figure 6). On the contrary, the control mice showed increased IL-10 expression after $24 \mathrm{~h}$. Interestingly, the contrast effect was also observed in EVOO-treated mice after 24h. EVOO increased the IL-10 expression in LPS-induced mice, but the IL-10 expression was decreased in control mice. Nevertheless, this result might be explained by another study showing that blockade of endogenous TNF-? may lead to increased production of IL-10. It was clear in this study that EVOO nanoemulsion decreased TNF-? expression after $8 \mathrm{~h}$, nonetheless the effect on IL-10 expression was observed later after $24 \mathrm{~h}$. Other studies also showed the ability of certain drugs, i.e., cyclosporin (Durez et al., 1993) and chlorpromazine (Mengozzi et al., 1994), to potentiate the release of LPS-induced IL10, which correlated to its suppressive effect on TNF-?

SP-D expression remained similar after 8h, but it was significantly lower after 24h in LPS-induced mice. Treatment with EVOO nanoemulsion decreased the SP-D expression significantly after $24 \mathrm{~h}$ in LPSinduced mice. SP-D plays a pivotal role in the innate immunity and the regulation of inflammatory responses in various infectious diseases (Du et al., 2018; Wright, 2005). A study on the role of SP-D in acute kidney injury showed that SP-D attenuates acute kidney injury (AKI) in sepsis by modulating renal apoptosis, inflammation, and NF- $\mathrm{KB}$ signaling (Du et al., 2018). The exact mechanism of EVOO nanoemulsion that triggered a decrease in serum SP-D levels was unclear. Nonetheless, this result supports the positive outcome of EVOO nanoemulsion in reducing the excessive inflammatory response in LPS-induced mice.

\section{CONCLUSION}

The effect of giving EVOO nanoemulsion through the enteral route of endotoxemia mice occurred 24th hour after administration. This phenomenon probably indicates that enteral absorption of EVOO nanoemulsion can occur through endotoxemia mice. The mechanism that causes this decrease in circulating SP-D levels is probably via pro-inflammatory and anti-inflammatory cytokine pathways. Further research needs to be continued to explore other paths, for example, genetics, the nature of the infecting pathogen, or environmental factors that may also affect SP-D levels.

\section{REFERENCES}

Amiot, F., Fitting, C., Tracey, K.J., Cavaillon, J.M., Dautry, F., 1997. Lipopolysaccharide-induced cytokine cascade and lethality in LT $\alpha /$ TNF $\alpha$ - deficient mice. Mol. Med. 3, 864-875. https://doi.org/10.1007/bf03401722 
RSF Conference Series: Medical and Health Science, Vol. 1 (1), 135-145

Extra Virgin Olive Oil Nanoemulsion Attenuated Inflammatory Response in LPS-Induced Sepsis

Anna Surgean Veterini, Nancy Margarita Rehatta, Subijanto Marto Soedarmo, Heni Rachmawati, Widjiati, Widodo Jatim P, Annis Catur Adi, I Ketut Sudiana

Barsig, J., Küsters, S., Vogt, K., Volk, H.D., Tiegs, G., Wendel, A., 1995. Lipopolysaccharideinduced interleukin-10 in mice: role of endogenous tumor necrosis factor-alpha. Eur. J. Immunol. 25, 2888-2893. https://doi.org/10.1002/eji.1830251027

Bayram, B., Esatbeyoglu, T., Schulze, N., Ozcelik, B., Frank, J., Rimbach, G., 2012. Comprehensive Analysis of Polyphenols in 55 Extra Virgin Olive Oils by HPLC-ECD and Their Correlation with Antioxidant Activities. Plant Foods Hum. Nutr. 67, 326-336. https://doi.org/10.1007/s11130-012-0315-z

Carpi, S., Scoditti, E., Massaro, M., Polini, B., Manera, C., Digiacomo, M., Esposito Salsano, J., Poli, G., Tuccinardi, T., Doccini, S., Santorelli, F.M., Carluccio, M.A., Macchia, M., Wabitsch, M., De Caterina, R., Nieri, P., 2019. The Extra-Virgin Olive Oil Polyphenols Oleocanthal and Oleacein Counteract Inflammation-Related Gene and miRNA Expression in Adipocytes by Attenuating NFкB Activation. Nutrients 11. https://doi.org/10.3390/nu11122855

Charlton, M., Thompson, J.P., 2019. Pharmacokinetics in sepsis. BJA Educ. 19, 7-13. https://doi.org/10.1016/j.bjae.2018.09.006

Curtis, A.M., Fagundes, C.T., Yang, G., Palsson-McDermott, E.M., Wochal, P., McGettrick, A.F., Foley, N.H., Early, J.O., Chen, L., Zhang, H., Xue, C., Geiger, S.S., Hokamp, K., Reilly, M.P., Coogan, A.N., Vigorito, E., FitzGerald, G.A., O'Neill, L.A.J., 2015. Circadian control of innate immunity in macrophages by miR-155 targeting Bmal1. Proc. Natl. Acad. Sci. U. S. A. 112, 7231-7236. https://doi.org/10.1073/pnas.1501327112

D’Angelo, S., Manna, C., Migliardi, V., Mazzoni, O., Morrica, P., Capasso, G., Pontoni, G., Galletti, P., Zappia, V., 2001. Pharmacokinetics and Metabolism of Hydroxytyrosol, a Natural Antioxidant from Olive Oil. Drug Metab. Dispos. 29, 1492 LP - 1498.

Du, J., Abdel-Razek, O., Shi, Q., Hu, F., Ding, G., Cooney, R.N., Wang, G., 2018. Surfactant protein $\mathrm{D}$ attenuates acute lung and kidney injuries in pneumonia-induced sepsis through modulating apoptosis, inflammation and NF-кB signaling. Sci. Rep. 8, 1-14. https://doi.org/10.1038/s41598018-33828-7

Durez, P., Abramowicz, D., Gérard, C., Van Mechelen, M., Amraoui, Z., Dubois, C., Leo, O., Velu, T., Goldman, M., 1993. In vivo induction of interleukin 10 by anti-CD3 monoclonal antibody or bacterial lipopolysaccharide: differential modulation by cyclosporin A. J. Exp. Med. 177, 551-555. https://doi.org/10.1084/jem.177.2.551

El Kamouni, S., El Kebbaj, R., Andreoletti, P., El Ktaibi, A., Rharrassi, I., Essamadi, A., El Kebbaj, M.S., Mandard, S., Latruffe, N., Vamecq, J., Nasser, B., Cherkaoui-Malki, M., 2017. Protective Effect of Argan and Olive Oils against LPS-Induced Oxidative Stress and Inflammation in Mice Livers. Int. J. Mol. Sci. 18. https://doi.org/10.3390/ijms18102181

Eveillard, M., Soltner, C., Kempf, M., Saint-André, J.P., Lemarié, C., Randrianarivelo, C., Seifert, H., Wolff, M., Joly-Guillou, M.L., 2010. The virulence variability of different Acinetobacter baumannii strains in experimental pneumonia. J. Infect. 60, 154-161. https://doi.org/10.1016/j.jinf.2009.09.004

Georgescu, A.M., Banescu, C., Azamfirei, R., Hutanu, A., Moldovan, V., Badea, I., Voidazan, S., Dobreanu, M., Chirtes, I.R., Azamfirei, L., 2020. Evaluation of TNF- $\alpha$ genetic polymorphisms as predictors for sepsis susceptibility and progression. BMC Infect. Dis. 20, 221. https://doi.org/10.1186/s12879-020-4910-6 
Girardin, E., Grau, G.E., Dayer, J.M., Roux-Lombard, P., Lambert, P.H., 1988. Tumor necrosis factor and interleukin-1 in the serum of children with severe infectious purpura. N. Engl. J. Med. 319, 397-400. https://doi.org/10.1056/NEJM198808183190703

Gonçalves, M.C., Horewicz, V.V., Lückemeyer, D.D., Prudente, A.S., Assreuy, J., 2017. Experimental Sepsis Severity Score Associated to Mortality and Bacterial Spreading is Related to Bacterial Load and Inflammatory Profile of Different Tissues. https://doi.org/10.1007/s10753017-0596-3

Jimenez-Lopez, C., Carpena, M., Lourenço-Lopes, C., Gallardo-Gomez, M., Lorenzo, J.M., Barba, F.J., Prieto, M.A., Simal-Gandara, J., 2020. Bioactive Compounds and Quality of Extra Virgin Olive Oil. Foods (Basel, Switzerland) 9. https://doi.org/10.3390/foods9081014

Kothari, N., Bogra, J., Abbas, H., Kohli, M., Malik, A., Kothari, D., Srivastava, S., Singh, P.K., 2013. Tumor necrosis factor gene polymorphism results in high TNF level in sepsis and septic shock. Cytokine 61, 676-681. https://doi.org/10.1016/j.cyto.2012.11.016

Makiuchi, A., Yamaura, K., Mizuno, S., Matsumoto, K., 2007. Hepatocyte Growth Factor Prevents Pulmonary Ischemia - Reperfusion Injury in Mice. J. Hear. Lung Transplant. 26, 935-943. https://doi.org/10.1016/j.healun.2007.06.010

Medeiros-De-Moraes, I.M., Gonçalves-De-Albuquerque, C.F., Kurz, A.R.M., De Jesus Oliveira, F.M., Pereira de Abreu, V.H., Torres, R.C., Carvalho, V.F., Estato, V., Bozza, P.T., Sperandio, M., De Castro-Faria-Neto, H.C., Silva, A.R., 2018. Omega-9 oleic acid, the main compound of olive oil, mitigates inflammation during experimental sepsis. Oxid. Med. Cell. Longev. 2018. https://doi.org/10.1155/2018/6053492

Mengozzi, M., Fantuzzi, G., Faggioni, R., Marchant, A., Goldman, M., Orencole, S., Clark, B.D., Sironi, M., Benigni, F., Ghezzi, P., 1994. Chlorpromazine specifically inhibits peripheral and brain TNF production, and up-regulates IL-10 production, in mice. Immunology 82, 207-210.

Otani, S., Coopersmith, C.M., 2019. Gut integrity in critical illness. J. Intensive Care 7, 17. https://doi.org/10.1186/s40560-019-0372-6

Schulte, W., Bernhagen, J., Bucala, R., 2013. Cytokines in sepsis: potent immunoregulators and potential therapeutic targets--an updated view. Mediators Inflamm. 2013, 165974. https://doi.org/10.1155/2013/165974

Siddique, A.B., Ebrahim, H., Mohyeldin, M., Qusa, M., Batarseh, Y., Fayyad, A., Tajmim, A., Nazzal, S., Kaddoumi, A., El Sayed, K., 2019. Novel liquid-liquid extraction and self-emulsion methods for simplified isolation of extra-virgin olive oil phenolics with emphasis on (-)-oleocanthal and its oral anti-breast cancer activity. PLoS One 14, e0214798. https://doi.org/10.1371/journal.pone.0214798

van Haren, F.M.P., Sleigh, J.W., Pickkers, P., Van der Hoeven, J.G., 2007. Gastrointestinal perfusion in septic shock. Anaesth. Intensive Care 35, 679-694. https://doi.org/10.1177/0310057X0703500505

Wright, J.R., 2005. Immunoregulatory functions of surfactant proteins. Nat. Rev. Immunol. 5, 58-68. https://doi.org/10.1038/nri1528

Yeo, M.K., Kim, H.E., Kim, S.H., Chae, B.J., Song, B.J., Lee, A., 2017. Clinical usefulness of the free web-based image analysis application ImmunoRatio for assessment of Ki-67 labelling index in breast cancer. J. Clin. Pathol. 70, 715-719. https://doi.org/10.1136/jclinpath-2016-204162 